\title{
Gastroesophageal reflux in patients with angiographically normal coronary arteries: an uncommon cause of exertional chest pain
}

Department of Cardiology,

R A Cooke

J B Chambers

Department of

Surgery,

A Anggiansah

W J Owen

Department of Public

Health Medicine,

Guy's Hospital,

London

N C Smeeton

Correspondence to:

Dr R A Cooke, Department

of Cardiology, Guy's

Hospital, St Thomas Street London SE1 9RT

Accepted for publication 16 March 1994

\begin{abstract}
Objectives-To investigate the association between exertional chest pain and gastroesophageal reflux in patients with normal coronary angiograms and in controls by measuring oesophageal pH during treadmill exercise tests and to compare the results with routine ambulatory monitoring.

Design-Case control study.

Setting-Tertiary referral cardiac unit.

Patients-50 consecutive patients with chest pain and completely normal coronary angiograms and 16 controls with coronary artery stenoses.

Main outcome measures-Episodes of acid reflux and chest pain during treadmill exercise; a symptom index expressing the percentage of episodes of pain related to acid reflux during ambulatory monitoring.
\end{abstract}

Results-Four (8\%) patients and two (12\%) controls had reflux during treadmill exercise (NS). 32 (64\%) and 16 $(100 \%)$ reported chest pain, but only three $(6 \%)$ and two $(12 \%)$ had coincident reflux (NS). Reflux was as frequent before, during, and after treadmill exercise (five $(8 \%) v \operatorname{six}(9 \%) v$ two $(3 \%)$ ) in the 66 subjects; (NS). 19 (38\%) patients and three $(19 \%)$ controls had abnormal reflux on ambulatory monitoring (NS). Eight (16\%) and three (19\%) had a symptom index $>50 \%$, but six and two of these reported pain without coincident reflux during treadmill exercise.

Conclusion-There are many potential causes of chest pain in patients with angiographically normal coronary arteries. Although gastroesophageal reflux is commonly implicated and many patients have a high incidence of spontaneous reflux during ambulatory monitoring, it

Table 1 Demographic data

\begin{tabular}{llll}
\hline & Patients $(n=50)$ & Controls $(n=16)$ & Pvalue \\
\hline Mean (range) age (yr) & $53(32-72)$ & $58(48-70)$ & NS \\
Sex (M/F) & $20 / 30$ & $12 / 4$ & $<0.05$ \\
Mean (SD) duration of symptoms (yr) & $3 \cdot 4(4 \cdot 3)$ & $4 \cdot 3(5 \cdot 2)$ & NS \\
Frequency of symptoms: & $26(52)$ & $6(38)$ & NS \\
Daily (n (\%)) & $19(38)$ & $5(31)$ & NS \\
Weekly (n (\%)) & $9(18)$ & $3(19)$ & NS \\
Current smoker (n (\%)) & $1(2)$ & 0 & NS \\
Diabetes mellitus (n (\%)) & $1(2)$ & $5(31)$ & $<0.05$ \\
Blood pressure > 160/95 mm Hg (n(\%)) & $20(40)$ & $6(38)$ & NS \\
Heartburn (n (\%)) & & & \\
\hline
\end{tabular}

Current smoker defined as smoking $\geqslant 5$ cigarettes/day in past year. rarely occurs during exertion and the association with chest pain is poor.

(Br Heart f 1994;72:231-236)

Normal or near normal coronary anatomy is found in up to $20 \%$ of patients undergoing coronary angiography for the investigation of exertional chest pain. ${ }^{12}$ Although long term survival is excellent, many patients have persistent symptoms despite reassurance and hence represent a continuing drain on resources. ${ }^{3-5}$ The mechanism giving rise to the pain, which is unlikely to be unitary, continues to be debated. Although there is increasing evidence of microvascular angina in selected patients, ${ }^{6-8}$ in clinical practice noncardiac causes are likely to be more prevalent. ${ }^{5}$

Gastroesophageal reflux is commonly implicated as the cause, ${ }^{9-11}$ but is typically associated with pain at rest or in relation to changes in posture. Although reflux during exercise may occur, ${ }^{12} 13$ only a few studies have investigated its association with chest pain. Schofield et al reported an association in $44 \%$ of patients, but the study was uncontrolled and the methods used to measure oesophageal $\mathrm{pH}$ are open to criticism. ${ }^{14}$ Other studies have involved only small numbers of patients and have produced conflicting results. ${ }^{15-17}$

Our study was designed to investigate the association between chest pain and gastroesophageal reflux during treadmill exercise tests, and to compare this with ambulatory monitoring. A large consecutive series of patients with normal angiograms was studied with standard methods to measure oesophageal $\mathrm{pH}$, and the results were compared with a small group of controls with ischaemic chest pain.

Patients and methods

PATIENTS

Between March 1990 and April 1991, out of 1022 patients in whom coronary angiography was performed for the diagnosis of new chest pain at Guys' Hospital, $84(8 \cdot 2 \%)$ had completely normal anatomy. Of these, 50 patients (table 1) whose principal complaint was exertional pain were recruited after exclusion of mitral valve prolapse (three patients), left ventricular hypertrophy (four patients), previous myocardial infarction (five patients), and 
abnormalities of resting wall motion on echocardiography as assessed by eye (five patients). A further nine patients reported pain at rest only, one was unable to exercise, and seven declined further investigation. All coronary angiograms were reported by two experienced cardiologists before entry into the study. Only patients whose coronary arteries were completely normal were included.

Sixteen patients with angina associated with ST segment depression and obstructive coronary artery disease $(>70 \%$ luminal diameter stenosis of at least one major epicardial artery by visual assessment) were recruited as controls (table 1). All had stable symptoms, and none had disease of the proximal left anterior descending artery or left main stem. Two had involvement of a single major epicardial artery only, and the remainder had either two or three vessel disease.

No patient or control was taking regular medication for acid reflux, or had been previously assessed by a gastroenterologist. All medication was stopped at least 48 hours before, and was omitted during the study period. The study was approved by the hospital's ethics committee and written informed consent was obtained.

\section{METHODS}

Oesophageal tests

Oesophageal tests were performed after a four hour fast. The lower oesophageal sphincter was located manometrically by the station pull through technique with a $2.5 \mathrm{~mm}$ diameter probe (Gaeltec, Scotland) with six catheter mounted microtransducers spaced at $5 \mathrm{~cm}$ intervals from the tip. The probe was withdrawn from the stomach in $1 \mathrm{~cm}$ stages and the upper limit of the lower oesophageal sphincter was marked by its distance from the outside nares. An average of four measurements was taken. Sphincteric pressure was measured in a standard way. ${ }^{18}$

A smaller $(2 \cdot 1 \mathrm{~mm}$ external diameter $)$ probe for ambulatory $\mathrm{pH}$ monitoring was then substituted. This contained a distal monocrystalline antimony $\mathrm{pH}$ sensor (Synectics) that was positioned $5 \mathrm{~cm}$ cephalad to the upper margin of the lower oesophageal sphincter. An external cutaneous electrode was used for reference, and changes in distal oesophageal $\mathrm{pH}$ were recorded on a portable solid state recorder (Synectics digitrapper) that was strapped around the subject's waist. The system was calibrated at $\mathrm{pH} 1.0$ and $7 \cdot 0$ (Synectics buffer solution) before insertion, and gastric acidity confirmed by passing the probe into the stomach before its final place-

Table 2 Exercise data

\begin{tabular}{llll}
\hline Variable & Patients & Controls & P value \\
\hline Mean (SD) exercise duration (min) & $8 \cdot 9(2 \cdot 7)$ & $6 \cdot 4(2 \cdot 5)$ & 0.002 \\
Mean (SD) HR.BP at rest (beats/min. mm Hg. 103) & $11 \cdot 3(2 \cdot 6)$ & $11.3(3.5)$ & NS \\
Mean (SD) HR.BP peak (beats/min. mm Hg. $\left.10^{3}\right)$ & $27 \cdot 4(7 \cdot 2)$ & $24 \cdot 1(6 \cdot 8)$ & NS \\
Chest pain (n (\%)) & $32(64)$ & $16(100)$ & $<0.005$ \\
Exercise electrocardiogram: & $10(20)$ & $15(94)$ & $<0 \cdot 001$ \\
ST depression $\geqslant 0 \cdot 10 \mathrm{mV}(\mathrm{n}(\%))$ & $3(6)$ & $1(6)$ & $\mathrm{NS}$ \\
LBBB (n (\%)) & &
\end{tabular}

HR, heart rate; BP, blood pressure; LBBB, left bundle branch block. ment above the lower oesophageal sphincter. The probe was secured by tape to the outside nostril.

A diary card and an event marker button were used to record the time of onset of symptoms that occurred spontaneously during the 24 hour ambulatory monitoring period. The event marker was also pressed before and after treadmill exercise. Alcohol, food, and beverages with $\mathrm{pH}$ values $<5$ were avoided, but otherwise subjects were unrestricted.

\section{Exercise tests}

Treadmill exercise tests were performed during ambulatory oesophageal $\mathrm{pH}$ monitoring. Subjects were asked to sit upright for $10 \mathrm{~min}$ utes before exercise tests so that the incidence of gastroesophageal reflux at rest could be compared with exercise. Nine $(16 \%)$ patients and nine $(57 \%)$ controls were postprandial (within two hours of a meal). A standard Bruce protocol was used during which all subjects were asked to walk rather than run, and to report the occurrence of any symptoms. Exercise was voluntary and maximal. Significant ST segment depression was defined as planar or downsloping ST segment depression of $\geqslant 0.1 \mathrm{mV}$ occurring $80 \mathrm{~ms}$ after the $J$ point and present on three consecutive beats.

\section{DATA ANALYSIS}

The stored data were transferred from the digitrapper to an IBM compatible personal computer for graphical display and numerical analysis with commercially available software (Esophogram Ver 5.5, Gastrosoft, Dunvegan, Scotland). Every record was visually checked to exclude artifact. A reflux episode was defined as any fall in distal gastroesophageal $\mathrm{pH}$ below a threshold of $\mathrm{pH} 4$ for more than 10 seconds. Abnormal reflux during 24 hour ambulatory monitoring was present where oesophageal $\mathrm{pH}$ was $<4$ for more than $5.5 \%$ of the study period. ${ }^{19}$ The number of patients who experienced a reflux episode, the percentage time oesophageal $\mathrm{pH}$ was below a threshold of $\mathrm{pH} \mathrm{4}$, and the minimum $\mathrm{pH}$ were compared in the rest, exercise, and recovery periods.

A symptom index for episodes of chest pain occurring spontaneously other than during treadmill tests was expressed. This was calculated for each subject by dividing the number of episodes of pain that were temporally related to gastroesophageal reflux by the total number of episodes of pain. ${ }^{20} \mathrm{~A}$ temporal relation was defined where chest pain occurred either within two minutes of a reflux episode, or if reflux occurred during the first two minutes of the onset of chest pain. A symptom index of $50 \%$ or more suggests that gastroesophageal reflux is a likely cause of symptoms. ${ }^{2122}$

\section{STATISTICS}

The $\chi^{2}$ and Fisher exact tests were used to compare independent discrete variables, and Student's two tailed $t$ test was used to compare continuous variables. The percentage 
Table 3 Reflux and chest pain dato

\begin{tabular}{lccl}
\hline & $\begin{array}{c}\text { Patients } \\
(n=50)\end{array}$ & $\begin{array}{c}\text { Controls } \\
(n=16)\end{array}$ & $\begin{array}{l}P \text { value } \\
\left(\chi^{2} \text { test }\right)\end{array}$ \\
\hline Abnormal reflux (n (\%)) & $19(38)$ & $3(19)$ & NS \\
Reflux during treadmill exercise (n (\%)) & $4(8)$ & $2(12)$ & NS \\
Chest pain during treadmill exercise (n (\%)): & $3(6)$ & $2(12)$ & NS \\
$\quad$ With reflux & $29(58)$ & $14(88)$ & NS \\
$\quad$ Without reflux & $8(16)$ & $2(12)$ & NS \\
Chest pain during ambulatory monitoring (n (\%)): & $21(42)$ & $5(31)$ & NS \\
$\quad$ Symptom index $\geqslant 50 \%$ & & \\
Symptom index $<50 \%$ &
\end{tabular}

Figure 1 Oesophageal pH recordings during treadmill exercise tests. (A) Is an example of chest pain without, and (B) an example of chest pain with coincident reflux. The bar indicates the exercise

period. In (A) the event marker was pressed in the recovery period for confirmation of timing.

Figure 2 Oesophageal pH recordings in a patient with normal coronary anatomy. (A) Chest pain was coincident with gastroesophageal reflux during treadmill exercise. Note, however, that an episode of asymptomatic reflux occurred before treadmill exercise. (B) $A$ spontaneous episode of chest pain during 24 ambulatory monitoring was temporally related to an episode of reflux. The

symptom index was $100 \%$. The bar indicates the exercise period in $(A)$. $P$ onset of pain in $(B)$. time oesophageal $\mathrm{pH}$ was $<\mathrm{pH} 4$ and the minimum $\mathrm{pH}$ were compared at rest, during exercise, and in recovery by Friedman's two way analysis of variance, and the proportion of patients who had reflux in each period by the Cochran $Q$ test. A $P$ value $<0.05$ was considered statistically significant.

\section{Results}

Table 2 shows the exercise data. Four (8\%) patients and two $(12 \%)$ controls had reflux during treadmill exercise (NS). Thirty two $(64 \%)$ and $16(100 \%)$ reported chest pain, but only three $(6 \%)$ and two $(12 \%)$ had coincident reflux (NS, table 3, fig 1 ). In no patient or control did oesophageal $\mathrm{pH}$ drop more than $1 \mathrm{pH}$ unit without falling below the threshold of $\mathrm{pH} 4$. 
Table 4 Reflux variables 10 minutes before (at rest), during exercise, and 10 minutes after (recovery) treadmill tests of 50 patients and 16 controls combined

\begin{tabular}{|c|c|c|c|c|}
\hline & $\begin{array}{l}\text { Rest } \\
(n=66)\end{array}$ & $\begin{array}{l}\text { Exeircise } \\
(n=66)\end{array}$ & $\begin{array}{l}\text { Recovery } \\
(n=66)\end{array}$ & Pvalue \\
\hline $\begin{array}{l}\text { With reflux (n }(\%)) \\
\text { Percentage time pH }<4 \\
\text { (mean (SD)) }\end{array}$ & $\begin{array}{l}5(8) \\
0.65(2.76)\end{array}$ & $\begin{array}{l}6(9) \\
2 \cdot 22(9 \cdot 43)\end{array}$ & $\begin{array}{l}2(3) \\
2 \cdot 71(15 \cdot 34)\end{array}$ & $\begin{array}{l}\text { NS }^{\star} \\
\text { NSt }\end{array}$ \\
\hline Minimum pH (mean (SD)) & $5.61(1 \cdot 20)$ & $5.55(1.13)$ & $5.61(1.02)$ & $<0.0001 \uparrow$ \\
\hline
\end{tabular}

*P > 0.5; Cochran's $Q$ test $1 \cdot 56, \mathrm{DF} 2$.

†Friedman two way analysis of variance.

The proportion of patients and controls who had reflux before, during, and after treadmill exercise was similar (table 4, fig 2). The percentage time that oesophageal $\mathrm{pH}$ was below $\mathrm{pH} 4$ was greater during and after, compared with before exercise, but the differences were not significant (table 4 ). The minimum recorded $\mathrm{pH}$ was $0.15 \mathrm{pH}$ units less during, compared with before exercise $(P<0.0001$, table 4$)$.

None of the patients or controls who had reflux during treadmill exercise were postprandial. Their resting lower oesophageal sphincteric pressure was significantly lower than in those who had no reflux on exercise tests (mean (SD) $6.2(1.5)$ v $8.4(3.2) \mathrm{mm}$ $\mathrm{Hg}, \mathrm{P}=0.048: 95 \% \mathrm{CI} 0$ to 4 ). The mean (SD) intra-abdominal oesophageal length was $1.9(0.7)$ for those with no reflux and 1.8 $(0.5) \mathrm{cm}$ for those with reflux (NS).

COMPARISON WITH AMBULATORY MONTTORING Eight $(16 \%)$ patients and three $(19 \%)$ controls had a symptom index $\geqslant 50 \%$ (table 3 ), but six and two of these reported chest pain without coincident reflux during treadmill tests. Only one patient and one control had both coincident reflux and a symptom index $\geqslant 50 \%$ (fig 2).

Nineteen (38\%) patients and three (19\%) controls had abnormal reflux (NS). Every patient, and one of two controls who had reflux during treadmill exercise had abnormal reflux. A similar proportion of patients with abnormal, compared with normal reflux reported chest pain during treadmill exercise (15 out of $19(80 \%) v 17$ out of $31(55 \%)$; NS).

\section{IMPORTANCE OF AN ABNORMAL EXERCISE \\ ELECTROCARDIOGRAM}

Patients with, and without significant ST segment depression or left bundle branch block on their exercise electrocardiogram, showed no significant differences in the proportion with abnormal reflux (four (31\%) v 15 $(41 \%))$, coincident reflux during treadmill testing (none $v$ three $(8 \%)$ ) or a symptom index $\geqslant 50 \%$ (two out of five (40\%) $v$ six out of $24(25 \%)$ patients with chest pain during monitoring).

\section{Discussion}

Gastroesophageal reflux may produce pain that is confused with angina, ${ }^{23}{ }^{24}$ or even provoke angina by causing a reflex fall in coronary blood flow. ${ }^{25}$ Although we found that spontaneous reflux was common during ambulatory monitoring both in patients with normal coronary angiograms and also in a small number of ischaemic controls, it was rarely associated with pain during exercise. Thus 32 (64\%) patients and $16(100 \%)$ controls reported pain during routine treadmill exercise tests, but only three patients (6\%) and two controls (12\%) had coincident reflux. Moreover, as many patients experienced reflux before as during and after exercise tests.

\section{COMPARISON WITH PREVIOUS STUDIES}

DeMeester et al and Thorpe both reported anecdotally that gastroesophageal reflux could occur during treadmill tests. ${ }^{15}{ }^{16}$ Schofield et al reported gastroesophageal reflux in 23 out of $52(44 \%)$ patients with normal coronary arteries. ${ }^{14}$ This coincided with the onset of chest pain in all but one. By comparison, despite a higher proportion of patients with abnormal reflux on 24 hour ambulatory monitoring in our study group compared with that of Schofield et al (38\% v 21\%), reflux during treadmill exercise occurred in only four $(8 \%)$.

It is unlikely that we failed to detect significant exertional gastroesophageal reflux in these patients. Oesophageal $\mathrm{pH}$ was sampled every four seconds and the response time was less than two seconds. The $\mathrm{pH}$ sensor was carefully positioned $5 \mathrm{~cm}$ above the manometrically determined lower oesophageal sphincter. This is an accepted and well validated method. ${ }^{26}$ But in the study by Schofield et al, the location of the $\mathrm{pH}$ sensor was determined by fluoroscopy. This will result in variable probe positions above the sphincter or even below it in the stomach if the patient has a hiatal hernia. ${ }^{27}$ The closer the $\mathrm{pH}$ sensor is to the lower oesophageal sphincter the greater the amount of reflux that is detected. ${ }^{18}$ But if the sensor is positioned $<5 \mathrm{~cm}$ above the sphincter there is at least a theoretical risk of it prolapsing into the stomach and producing a spurious fall in $\mathrm{pH} .{ }^{28}$

In agreement with our findings and with similar methods Lehman and Farris studied 21 patients with normal coronary angiograms and found no instances of gastroesophageal reflux during treadmill exercise tests despite the presence of abnormal gastroesophageal reflux in most cases as shown by other manoeuvres. ${ }^{17}$

Gastroesophageal reflux has been shown to be provoked by vigorous exercise in healthy young volunteers. ${ }^{1213}$ All our patients were instructed to walk to avoid the potentially confounding influence of more vigorous exercise. The finding that reflux was as frequent before, as during and after exercise suggests that treadmill exercise was not a cause of acid reflux. Although the mean percentage duration that oesophageal $\mathrm{pH}$ was below $\mathrm{pH} 4$ was higher during exercise and in recovery than in the rest period, the absolute differences were small (NS). There was, however, a significant fall in oesophageal $\mathrm{pH}$ during exercise, but this again was small and within experimental error. 
RELEVANCE OF ACID REFLUX IN CONTROLS

The finding of a temporal relation between reflux and chest pain during exercise tests in two controls is open to interpretation. In one of these, and in another control who did not have coincident reflux during treadmill tests, the symptom index was $\geqslant 50 \%$. As all had symptoms typical of angina associated with significant ST segment depression, there is little doubt that their pain was due to cardiac ischaemia. There is some evidence that gastroesophageal reflux may lower the anginal threshold, and it is therefore possible that there was an interaction in these cases. ${ }^{29}$ Alternatively, the association may have been coincidental.

A higher proportion of controls than study patients were postprandial during the exercise tests. Although one might have expected a higher incidence of reflux in these, than in fasting subjects, ${ }^{30}$ in fact reflux was found in none of the 18 (nine patients, nine controls) postprandial subjects. The similar incidence of treadmill reflux in controls therefore cannot be attributed to a greater proportion who were postprandial.

The incidence of abnormal reflux during ambulatory monitoring was less in controls than study patients (three $(19 \%) v 19(38 \%)$ ). Although it is tempting to interpret this as suggesting that reflux may be clinically important in the group with normal anatomy, the difference did not attain significance. The number of controls was small as patients with coronary artery disease are understandably reluctant to undergo oesophageal tests where this is unlikely to be of direct benefit to them. No conclusion, therefore, should be drawn about the relative incidence of abnormal reflux in patients with and without coronary artery disease.

\section{TEMPORAL CORRELATION}

The overall temporal correlation between chest pain and gastroesophageal reflux was poor. In only 10 out of $40(25 \%)$ patients who reported at least one episode of chest pain during the study period was there either coincident reflux during treadmill exercise, a symptom index of $\geqslant 50 \%$, or both. A similar temporal correlation was found in the small group of controls. Moreover, most patients who had a symptom index $\geqslant 50 \%$ reported pain during treadmill exercise without coincident reflux.

The simultaneous occurrence of chest pain and gastroesophageal reflux although consistent with a causative relation may still be explained by chance. Where chest pain occurs consistently at a time when oesophageal $\mathrm{pH}$ is normal, then despite the presence of abnormal reflux at other times it is reasonable to conclude that the patient's symptoms are not due to reflux alone.

The possibility of more complex interactions cannot be ruled out. For instance acid reflux may sensitise the oesophagus and reduce the threshold for pain after a time delay. Of interest, however, patients with abnormal as opposed to normal reflux were not more likely to experience chest pain on treadmill tests. In some patients with an acid sensitive oesophagus chest pain may be provoked by only minor changes in oesophageal pH. ${ }^{31} 32$ In no patients, however, did oesophageal $\mathrm{pH}$ drop more than $1 \mathrm{pH}$ unit during treadmill tests without falling below the threshold of $\mathrm{pH} 4$ used to define a reflux episode.

In conclusion, there are many potential causes of chest pain in patients with angiographically normal coronary arteries. Although gastroesophageal reflux is commonly implicated, reports of its association with exertional chest pain are based almost solely on a single uncontrolled study with outdated methods. In our study, we used well validated methods and found a very low incidence of exertional reflux both in patients and a small number of controls with ischaemic chest pain. Moreover, reflux was as common before as during and after exercise, and its association with pain was poor both during ambulatory monitoring and exercise tests.

1 Proudfit WL, Shirey EK, Sones FM. Selective cine coronary arteriography: Correlation with clinical findings in 1000 patients. Circulation 1966;33:901-10.

2 Phibbs B, Fleming T, Ewy GA, et al. Frequency of normal coronary arteriograms in three academic medical centres and one community hospital. Am $f$ Cardiol 1988; 62:472-4.

3 Proudfit WL, Bruschke AV, Jones FM. Clinical course of patients with normal or slightly or moderately abnormal coronary arteriograms: 10 year follow-up of 521 patients. Circulation 1980;62:712-7.

4 Kemp HG, Kronmal RA, Vliestra RE, Frye RL. Seven year survival of patients with normal or near normal coronary angiograms: A CASS registry study. $f \mathrm{Am}$ Coll Cardiol 1986;7:479-83.

5 Chambers J, Bass C. Chest pain and normal coronary anatomy. Prog Cardiovasc Dis 1990;33:161-84.

6 Cannon RO, Cattau EL, Yakshe PN, et al. Coronary flow reserve, oesophageal motility, and chest pain in patients with angiographically normal coronary arteries. $\mathrm{Am}$ Med 1990;88:217-22.

7 Geltman EM, Henes CG, Senneff MJ, Sobel BE, Bergmann SR. Increased myocardial perfusion at rest and diminished perfusion reserve in patients with angina and diminished perfusion reserve in patients with angina and angiographically nor

8 Camici PG, Marraccini P, Lorenzoni R, et al. Coronary haemodynamics and myocardial metabolism in patient with syndrome X: response to pacing stress. $f \mathrm{Am} \mathrm{Coll}$ Cardiol 1991;17:1461-70.

9 Hick DG, Morrison JFB, Casey JF, Al-Ashhab W, Williams GJ, Davies GA. Oesophageal motility, lumina $\mathrm{pH}$, and electrocardiographic-ST segment analysis during spontaneous episodes of angina like chest pain. Gut 1991;33:79-86.

10 Breumelhof $R$, Nadorp JHS, Akkermans LMA, Smout AJPM. Analysis of 24 hour oesophageal pressure and $\mathrm{pH}$ data in unselected patients with non cardiac chest pain. Gastroenterology 1990;99:1257-64.

11 Soffer EE, Scalabrini P, Wingate DL. Spontaneous non cardiac chest pain: value of ambulatory oesophageal $\mathrm{pH}$ cardiac chest pain: value of ambulatory oesophageal pH

12 Clark S, Kraus BB, Sinclair J, Castell DO. Gastrooesophageal reflux induced by exercise in healthy volun oesophageal reflux induced by exercis

13 Yazaki E, Shawdon A, Beasley I, Evans D. The effect of different types of exercise on gastro-oesophageal reflux [abstr]. Gut 1992;166.

14 Schofield PM, Bennett DH, Whorwell PJ, et al. Exertiona gastro-oesophageal reflux: a mechanism for symptoms in patients with angina pectoris and normal coronary angiograms. $B M F$ 1987;294:1459-61.

15 DeMeester TR, O'Sullivan GC, Bermudez G, Midell AI, Cimochowski GE, O'Droinak JO. Oesophageal function in patients with angina type chest pain and normal coronary angiograms. Ann Surg 1982;196:488-98.

16 Thorpe A. Importance of oesophageal function tests in patients with angina like chest pain. Cardiology in Practice 1984;2:35-8.

17 Lehman GA, Farris JV. Observations for gastrooesophageal reflux during treadmill exercise testing [abstr]. Gastroenterology 1978;74:1054

18 Anggiansah A, Sumboonnanonda $K$, Wang J, Linsell J, Anggiansah A, Sumboonnanonda K, Wang J, Linsell J,
Hale P, Owen WJ. Significantly reduced acid detection at 10 centimetres compared to 5 centimetres above the Am $\mathcal{f}$ Gastroenterol 1993;88:842-6. 
19 Richter JE, Bradley LA, DeMeester TR, Wu WC. Normal 24 hour ambulatory oesophageal $\mathrm{pH}$ values. Influence of study centre, pH electrode, age, and gender. Dig Dis Sci 1992;37:849-56.

20 Weiner GJ, Richter JE, Copper JB, Wu WC, Castell DO. The symptom index: a clinically important parameter of ambulatory 24 hour oesophageal pH monitoring. $\mathrm{Am} \mathfrak{f}$ Gastroenterol 1988;83:358-61.

21 De Caesteker JS, Heading RC. Oesophageal pH monitoring. Gastroenterol Clin North Am 1990;19:645-69.

22 Howard PJ, Maher L, Heading RC. Symptomatic gastrooesophageal reflux, abnormal oesophageal acid exposure, and mucosal acid sensitivity are three separate, though related, aspects of gastro-oesophageal reflux disease. Gut 1991;32:128-32.

23 Kramer $P$, Hollander $W$. Comparison of experimental oesophageal pain with clinical pain of angina pectoris and oesophageal disease. Gastroenterology 1955;29: $719-43$.

24 Davies HA, Jones DB, Rhodes J, Newcombe RG. Anginalike chest oesophageal chest pain: differentiation from cardiac pain by history. $f$ Clin Gastroenterol 1985;7: cardiac

25 Chauhan A, Mullins PA, Taylor G, Petch MC, Schofield PM. The effect of oesophageal stimulation on coronary blood flow [abstr]. Br Heart $₹$ 1993;69(suppl):P63.
26 Anggiansah A, Bright $N$, McCullagh $M$, Sumboonnanonda $K$, Owen WJ. Alternative method of positioning the $\mathrm{pH}$ probe for oesophageal $\mathrm{pH}$ monitoring. Gut 1992;33:111-4.

27 Klauser AG, Schindlbeck NE, Muller-Lissner SA Oesophageal 24 hour pH monitoring: is pior manometry necessary for correct positioning of the electrode? $A m \mathcal{F}$ necessary for correct positioning

28 Cravens E, Lehman G, O'Connor $\mathrm{K}$, et al. Placement of oesophageal $\mathrm{pH}$ probes $5 \mathrm{~cm}$ above the lower oesophageal sphincter: can we get closer [abstract]? Gastroenterol 1987;92:1357.

29 Alban Davies H, Page Z, Rush EM. Oesophageal stimulation lowers external angina threshold. Lancet 1985;ii 1011-4.

30 Holloway RH, Hongo $M$, Berger $\mathrm{K}$, McCallum RW Gastric distension: a mechanism for postprandial gastroesophageal reflux. Gastroenterology 1985;89: 779-84.

31 Vantrappen G, Janssens G, Ghillebert G. The irritable oesophagus - a frequent cause of angina like pain. Lancet 1987;i:1232-4.

32 Lam HGT, Dekker W, Kan G, Breedijk M, Smout AJPM Acute non cardiac chest pain in a coronary care unit. Evaluation by 24 hour pressure and $\mathrm{pH}$ recording of the oesophagus. Gastroenterology 1992;102:453-60. 